\title{
ENTRE LA ABSTRACCIÓN, LA REALIDAD Y EL REALISMO. VLADY Y LA "GENERACIÓN INTERMEDIA"
}

\author{
(Evidencias siempre renovadas)
}

ELIA EsPinosa LóPEZ

Es necesario volver a considerar los conceptos de abstracción, realidad y realismo en intercambio constante, transformador y determinante respecto de la técnica pictórica y su importancia matérico-espiritual. Esos tres niveles tienden a confundirse "naturalmente" en las obras de arte (de aquí lo de "evidencias siempre renovadas"), tienden a separarse uno del otro por sutiles fronteras en las que se encuentra el desarrollo técnico, temático y todas sus implicaciones.

Propongo que se revaloren la abstracción y su relación con la realidad (convertida o no en "realismo" dentro de la obra) con respecto a la ima" gen y a la técnica como fenómenos en sí, inherentes al pensamiento, y como intercąmbio en el que la abstracción es una mecánica que tamiza y trasmuta la realidad, adquiriendo tantas índoles o especificidades como artistas que las inventan, desarrollan, agotan, y épocas y sociedades en que éstos viven.

¿Qué es abstraer? Es separar o dividir en el pensamiento lo indivisible en la realidad circundante. Es la magia fisio-nerviosa de la materia gris para transformar a nuestra guisa las ideas-destellos que el mundo objetual-subjetual hace surgir en nosotros, "retornándolas", a través de la acción y, aún con más precisión, evidentemente, de la práctica. La práctica es acto presente, ya sea cotidiano en el sentido de no tener pretensiones creativas específicas (llevado a cabo por todos nosotros sin excepción), ya sea artístico en el sentido de ser imaginativo-sensitivo-reflexivo.

Al contrario de lo que se cree comúnmente, el acto abstrayente - dinámica connatural al pensamiento - no sólo es intelectivo y racional, o no únicamente está regido por el intelecto o la inteligencia desde un punto de vista analítico; ¿cuántas veces en medio del entusiasmo que nos causa una idea (obviamente una imagen) no sabemos en dónde está, o no damos con la frontera en que dejó de ser íntegramente para irse sucediendo en una serie de abstracciones que la enriquecieron en la velocidad del pensamiento, como formando un "cine" interior? 
En su Abstracción y naturaleza, ${ }^{1}$ Wilhelm Worringer afirma que al abstraer estamos creando otra vida que nada tiene que ver con la vida orgánica a la cual tienden el realismo y el naturalismo; estamos originando una vida inorgánica, no sanguínea, ni humoral, ni transpirante, pero que tiene su propio movimiento, su propia organización espacial y espiritual.

La abstracción nace de una necesidad psíquica muy profunda de crear un propio orden ante la dinámica cambiante de la realidad exterior. Esa necesidad psíquica está determinada por la fuerza del "sentimiento vital"2 de cada sociedad, que opone este sentimiento a la vida irrefrenable y las mutaciones de la naturaleza; "...el afán de abstracción es consecuencia de una intensa inquietud interior del hombre ante esos fenómenos"3 no humanos, como el ascenso del sol y el crepúsculo, las tormentas, el frío, el calor. En cambio, el deseo o voluntad de proyección sentimental está condicionado por una venturosa y confiada comunicación panteísta entre el hombre y los fenómenos del mundo circundante. ${ }^{4}$ De aquí el paisaje realista, los "bodegones", las "naturalezas muertas", las "marinas" (a pesar de la bravura y potencia del mar).

Las tesis de Worringer son idealistas y románticas, su producción corresponde a los últimos grandes reductos del idealismo alemán hegeliano y nietzschiano. Sus propuestas carecen de un planteamiento sociológico y un sabor histórico que "limiten" su gran imaginación, la cual llega a ofrecer, incluso, el concepto de "agorafobia espiritual" que nos empuja, como última y primera instancia, a crear nuestro propio orden opuesto al natural.

Tómense con reserva sus tesis. Las he citado para hacer presentir la potencia de la abstracción en su relación con la vida y la actividad artística, sin pretender dar ni solución ni respuesta definitivas a un problema de tal envergadura vital e intelectual, ni a la manera en que los diversos pintores de que me ocuparé la han manejado.

Este ensayo es una "tercera llamada" (sí, como en el teatro) hacia la importancia de lo que he llamado "estar a medio camino" entre la abstracción, la realidad y el realismo en que se encuentra la pintura mexicana contemporánea, y el tipo de abstracción-realismo, realismo-abstracción que se levantan de las telas en que se manifiestan estas dualidades.

La problemática hasta aquí soslayada palpita en las obras de la "generación intermedia", así llama Teresa del Conde a los pintores que comenzaron a trabajar en el periodo que corre entre el de los pioneros de la pintura

\footnotetext{
${ }^{1}$ Wilhelm Worringer, Abstracción y naturaloza, México, FC.E., pp. 29-30.

2 Ibidem, p. 29

'Ibiden, p. 30

${ }^{4}$ Ibidem, p. 30
} 
"interiorista" de los años 50 y los jóvenes artistas de nuestros días, reuni. das en la exposición Alternancias, de diciembre de 1985 a enero de 1986, en el Museo de Arte Moderno de Chapultepec, y en la exposición de los últimos cuadros de Vlady (murales y de caballete) en el Palacio de Bellas Artes, que tuvo lugar de enero a febrero de 1986. Toda esta producción es una muestra fehaciente de cómo el informalismo, el figurativismo, el realismo (entendido como práctica cuyos resultados iconográficos son inmediatamente identificables en la realidad exterior) y todos los "ismos" de nuestra pintura actual, se mueven entre la abstracción, la realidad y el realismo en tanto procesos de experimentación artística y no en ninguno de ellos absoluta, limitada y definitivamente.

Se ha vuelto a la figuración y a un realismo figurativo, pero persiste una tendencia inevitable del artista a quedarse "a medio camino" entre la una y la otra. El "a medio camino" es la meta final. El artista delimita sus objetos pero tiende hacia la abstracción cuando sintetiza las formas, el color y su aplicación sobre la superficie. Las últimas obras de Vlady y algunas de Eduardo Tamariz, Ismael Guardado, Ricardo Rocha, Óscar Rodríguez y Susana Sierra son ejemplos de este impasse metodológico-plástico tan inquietante, tanto para el crítico como para el espectador y para la pintura misma, ya que de él puede depender su acceso a nuevas vías enriquecedoras hacia una nueva claridad o hacia una nueva perdición a largo o corto plazo.

\section{La "Generación intermedia". Algunos pintores}

Esta generación cuenta con artistas entre los 40 y 50 años de edad, hombres y mujeres en plenitud productiva, los cuales, como es natural, aunque formen parte de un proceso global desatado a principios de la década de 1950, como expusimos en la primera parte, guardan tendencias tanto de los primeros abstractos como del inseparable realismo al que ningún pintor mexicano ha escapado durante alguna de sus etapas de desarrollo. Tienen estos pintores el privilegio de producir obras cuyas consecuencias son como delgadas navajas fronterizas entre una fulguración y otra, un estado y otro, un abismo y otro de la materia en todos sus estados, ya invisibles o visibles, impalpables o palpables.

En Tenía miedo del aire y de la lluvia, Eduardo Tamariz pinta una máquina de hierro con oficio limpio y técnicas de veladuras, $u$ otras que requieren de gran concentración, acuciosidad y refinamiento visual y químico. Un azul cobalto se extiende rodeándola por medio de capas sutiles, permanece esfumado, pero cumpliendo sus funciones complementarias básicas respecto del objeto en el que despliega su función de azul; la inmediata frialdad, el 
distanciamiento, su contraposición necesaria al naranja. Esas masas de hierro con picos agresivos están suavizadas por "nubes" de color sumamente delicadas que acompañan la abstracción simbólica del miedo y la lluvia, representados por esos metales dentados. En ese cuadro, el pintor ha sido todo un maestro de la concreción plástica, de la oposición de intensidades diferentes, por medio del tratamiento y logro de especificidades y variadas densidades moleculares (hierro, aire, varitas de paja).

En Hastial, Ismael Guardado contrasta la brutalidad y el refinamiento de un geometrismo que recuerda los relieves sumerios o acadios, y que si bien es primitivo por la intromisión de huellas animales puras y sencillamente inmediatas, resulta antediluvianamente delicado. Esta obra presenta justamente un "término medio", una dualidad que pretende subrayar su unidad plástica. Lo mâs "reconocible" allí son las huellas de pies humanosanimales, animales-humanos sobre el barro húmedo. El resto de elementos es "reconocible", dentro de su semiología abstracta, significativa quizá de esotéricos contenidos que multiplican la complejidad de la relación abstracción-realidad, porque ésta queda, valga la redundancia, en un mero nivel abstracto determinado por una serie de infinitas posibilidades de interpretación.

Pintar informalmente conjuntos cromáticos violentos en los que van insertas frases lingüísticas que apoyan el grito o el susurro que pululan en las superficies, ésta es una de las manifestaciones de Susana Sierra. Abstracción cromática proveniente, primero, de la apretada abstracción de una emoción que empuja a que se le exteriorice y se le plasme y, segundo, del lenguaje mismo, abstracción rotunda que manejamos de la manera más natural en la vida cotidiana. En sus cuadros hay color, voz, sonido. Varias de sus obras son una superposición de abstracciones de origen sensitivo-emotivo-abismal que, simultáneamente, se hacen de una línea racional que rige el principio, el sentido de la consecución y el fin de las mismas; división, separación de emociones abstraídas del color, el sonido, la rebeldía sensual y sentimental contra toda forma que permanezca inmóvil dentro del artista y de la obra; el corazón es el mago del desenfreno creador en la obra y en la vida. Su Homenaje a Rilke, en cuyo centro aparece la frase "el corazón đesenfrenado", es un ejemplo de síntesis de la abstracción huracanada de lo que vive de suyo y de por sí, independientemente de la voluntad humana - como el corazón mismo-, así como de abstracción linguística y geométrica que sostiene el eco de la frase y el resuello de la vorágine emotiva. Como escribió Teresa del Conde: "... el propósito es producir una composición atectónica, cuyas leyes de organización obedecen a una poética muy personal y subjetiva por parte del artista, dirigida a establecer una comunicación 
predominantemente emocional entre obra-espectador. Éste 'concluye' el significado de la obra de acuerdo a sus propias motivaciones internas". "Producir una atectonicidad con sólo el peso ascendente de las sensaciones y las emociones.

Ricardo Rocha se mueve en la esencia dinámica e instantánea de los seres que florecen en su pintura. En Apunte del natural, trabaja una masa de árboles solitaria en medio de una estepa. Su pintura se levanta entre la esencia y la presencia de las cosas, ${ }^{6}$ en la línea intermedia que las une y a la vez las separa en pro de la diferencia. Su técnica en este cuadro es ilustrativa porque es experimental. Una masa oscura al centro es cercada por el cielo-valle claro, y es la dinámica diagonal del "raspado" de los colores sobre la tela lo que modula y diferencia los elementos; la claridad se aposenta para originar y singularizar las gradaciones de una misma totalidad. Rocha nos deja ver cómo la vida va construyendo a su paso, nos permite situarnos entre la ilusión, la realidad presencial y no nos provoca duda en que lo que presenta es absoluto, vértigo puro del movimiento de la gestación y de la gestación en movimiento. Su abstracción y realidad serian de tipo dinámico-interpresencial-esencial.

En Caballo negro tú tienes la cola roja, Óscar Rodríguez plantea una abstracción-realismo en que, al decir de Raúl Chávarri: “. . . se sueña lo que se pinta", 7 estableciendo la liga entre la materia de los sueños y la realidad palpable. Hay fantasmagoría y referencia a la realidad como "sucesión de planos" infinita. Su pintura es plástica de movimientos (valga la redundancia), no hay fijaciones, excepto las de punto de partida del subconsciente, de donde brota, paradójicamente, el movimiento plástico. Su abstracción sería de tipo subconsciente-fantástico-realista emparentada, cierto, con el ritmo del sueño.

\section{Vlady}

A pesar de los trece meses que han transcurrido desde la exposición de Vlady en el Palacio de Bellas Artes, acontecimiento fastuoso para la pin-

\footnotetext{
5 Teresa del Conde, "La neofiguración en México", en: Revista del Colegio de Bachilleres, No. 5, abril-junio, México, 1980. Si bien la autora no hace directamente objeto de su artículo la problemática fundamental que yo planteo en estas páginas, ya que trata principalmente la figuración, sí soslaya de varias maneras y en no pocos momentos la relación entre la abstracción y el tealismo

${ }^{6}$ Entiéndase el concepto de presencia como aquello que se inviste la esencia, el velo que la antecede o la continúa en su multiplicidad inaprehensible.

' Raúl Chávarti, citado en el catálogo de la exposición Alternancias La generación intermedia, México, Museo de Arte Modetno, diciembre 1985-febreto 1986, p. 40.
} 
tura mexicana, su obra es materia permanente de planteamientos sobre la relación entre la realidad y la abstracción, la abstracción y el realismo. Este aspecto lo une, a pesar de las diferencias de edad, vida, trayectoria artística (aunque no en sus años de abstracción pura) a la "generación intermedia".

Entrar a la exposición de Vlady era, aparte de la captación de la avalancha cromática que la invadía, un encuentro con la fuerza, la sutileza, la transparencia, el espesor, los volúmenes altos de los colores calientes (amarillos radiantes, ocres oro-antiguo, sienas), el uso de las tierras, los azules y los verdes, y también un encuentro con la fuerza embestidora del rojo, aglutinante de pasiones que, sobre la superficie, se conducen entre la línea circundante y el "caos" necesario hacia la abstracción (entre otros procesos que se consideran en estas páginas).

Es definitivo que Vlady, como los artistas a los que aludí en páginas anteriores, ha vuelto a la figuración realista reconocible (lo sintetizo de manera muy simple). Recordemos que el acto abstrayente es, además de intelectual, sobre todo instintivo, naturalmente fluido, es un acto como el de levantar un brazo, adelantar una pierna, guiñar un ojo. Resumiendo en sí mismo la tradición rusa y la germano-francesa, Vlady afirma: "La cabeza del artista está en su corazón" y: "hay algo de santidad en la pintura"; 8 ¿no es la santidad una de las más voraces abstracciones, tanto, que abstrae el cuerpo hacia una ortodoxia severa, convirtiéndolo en flecha que huye de sí misma? Estoy de acuerdo con Vlady: la abstracción es, tal vez, primeramente corazón, explosión entre la intuición y la capacidad de descubrir que todos poseemos, es decir: antes que raciocinio es vida; después, el intelecto la sistematiza.

Vlady divide, une, superpone, suscita transparencias, revuelve, convulsiona, estalla a partir de la pintura. Su "Exposición metodológica" es el ejemplo idóneo de la problemática implícita en mis proposiciones de revi. sión y reconsideración de la relación abstracción-realidad-realismo-técnica Leonardo da Jandra fue quien acertadamente dio título a la muestra, ya que de entrada nos sugiere aquella otra gran realidad que corre parejas con la mostración de un método: la experimentación; todo acto de abstracción con miras a ser plasmado en una obra implica, si no explícitamente, una especial importancia dada al método y la experimentación para llegar a ella, ya que no sabemos qué producirá la materia que seccionamos, dividimos o separamos, a pesar de tener un esquema de "arranque" que dirigirá el proceso de trabajo.

${ }^{8}$ Vlady Exposición metodológica, México, Museo del Palacio de Bellas Artes, Sala Nacional, enero-febrero, 1986, p. 3 
La exposición de Vlady pone al desnudo, con calidad y donaire grandes, tanto el movimiento que rige su talento artístico como todos sus afanes de hacernos ver sus procesos, vías de crecimiento cromático-intensivo, maduraciones, como más importantes que los contenidos, aunque éstos ofrezcan parcialmente una pauta para trabajar el conglomerado de fuerzas que acompaña toda concepción imaginario-sensitiva y su realización.

El artista despliega sus experimentos revivificadores e impulsores de la técnica y la percepción del espíritu constructivo de ésta, a partir de una temática plural que abarca desde la mitología griega y persa hasta la literatura romántica alemana, pasando por precipicios como el trágico Hamlet, o rozando cimas histórico-legendarias como un Jerjes o un Napoleón.

Pero todo ese desfile mágico-histórico parece un mero pretexto cultural ("culterano", escribe Teresa del Conde) "que exhibe la dimensión eruditainformativa del pintor. Busca y realiza lo que es su verdadera sabiduría en la investigación técnica-experimental que toma, renueva, multiplica, despierta de un letargo de siglos, con riqueza espléndida las complejas y refinadas técnicas de Tiziano, Rubens, Delacroix, Turner, entre otros, que desarrollaron a su manera los principios de la técnica veneciana de veladuras.

La carga histórica y carismática de los temas que maneja contribuye seguramente a que le sea imprescindible la abstracción esfumatoria, la búsqueda más allá de la figura, en los orígenes sensitivos del color y su fuerza propia. Esto da lugar a una hipótesis: su abstracción tiene un decidido principio semiótico dentro de todo un lenguaje constituido plásticamente; narración en potencia, sembrada en el poderío del color.

Tras la investigación técnica-experimental —la más fuerte a nuestro parecer en esa muestra-, auténtica piedra de toque para su trabajo, el pintor revela abstracciones cromático-intensivas. Dicho de otro modo: gusta de - y se le da - permanecer entre la abstracción no figurativa y un realismo proveniente de su sujeción al tema como kinesis significativa que no podrían ser el uno sin el otro; historia de amor de dos dinámicas, concreta en la ficción fehaciente y verdadera de la pintura.

Vlady llega a sus abstracciones-hazañas por medio de la superposición gozosa de delgados velos de pintura, cuya refracción conjunta origina tonalidades que otras técnicas son incapaces de producir. Les extrae nuevos torrentes energético-lumínicos que lo han llevado a un tipo de abstracción pasional o realismo vital abstrayente. En su Jerjes se encuentran apasionadas pinceladas rojas al lado de verdes espesos que circundan áreas en que

"Teresa del Conde, Catálogo de la Exposición Metodológica, p 3. 
la luz brota desde el fondo del cuadro, a través de cinco o quizá diez capas delgadas de pintura que se mezclan en nuestros ojos, como si se tratara de un "impresionismo" de atrás hacia adelante y no por yuxtaposición de tonos, tal en el impresionismo francés. Un dragón, otros seres y múltiples entelequias plásticas se ubican como manchas, figuras semirreconocibles, diversos espesores de pintura, diversos golpes y presiones de pincel que, de suyo, propician que Vlady se mueva constantemente entre una abstracción muscular, sanguínea, que llega desde las raíces carnales del temperamento - resultado de un impulso culterano/vitalista- y de un reconocimiento mágico-poético-amoroso de las cosas:" " $\mathrm{El}$ afecto está en todo!. . . Una mano da a entender un brazo, un pie insinúa la pierna... El brillo es luz. Lo mate es color. . . Un 'feo' violeta o un verde 'feo' son bellos si se ponen con afecto... Lo neutro es centelleante si el sentimiento lo quiere. Los brillos son el cariño del rayo luminoso. .."10

Como algunos de los artistas neoclásicos franceses de los años 20 (Picasso, Cocteau, Stravinsky, etc.), el pintor ruso-mexicano ha hecho innovaciones profundas partiendo de la tradición, una tradición que además declara amar, defender y enaltecer como a un manantial caudaloso y refrescante, gestador de renacimientos. Su abstracción, su realismo y su realidad han sido excavados de nuevo a partir de decisiones interiores, pero también de los azares de la técnica misma a lo largo de la elaboración, y están situados en un regreso odiseico, por su belleza oriunda de una victoria a través de siglos, de obstáculos sociales, políticos, de individualidades determinantes. Pero también han permitido contemplar la matriz de un método y han hecho revalorar esas instancias no como fines, sino como quehaceres que sólo cobran sentido si los consideramos en su propio punto medio. ¿No es esto un nuevo trabajo de Hércules en un mundo neuróti-camente veloz, en que la tradición nos pisa los talones al mismo tiempo que aplastamos con pie completo lo nuevo?

\section{Conclusiones}

Si nos guiamos por Worringer para cerrar nuestro artículo, diremos que la pintura mexicana vive entre una tendencia orgánica o proyección sentimental, y una corriente inorgánica o afán de abstracción de gran fuerza. De hecho, todo arte oscila entre estos dos polos, pero mayormente cuando la experimentación, método siempre renovado y siempre viejo en el instante, caracteriza los derroteros de ese arte y sus artistas.

${ }^{10}$ Ibidem, p 12 


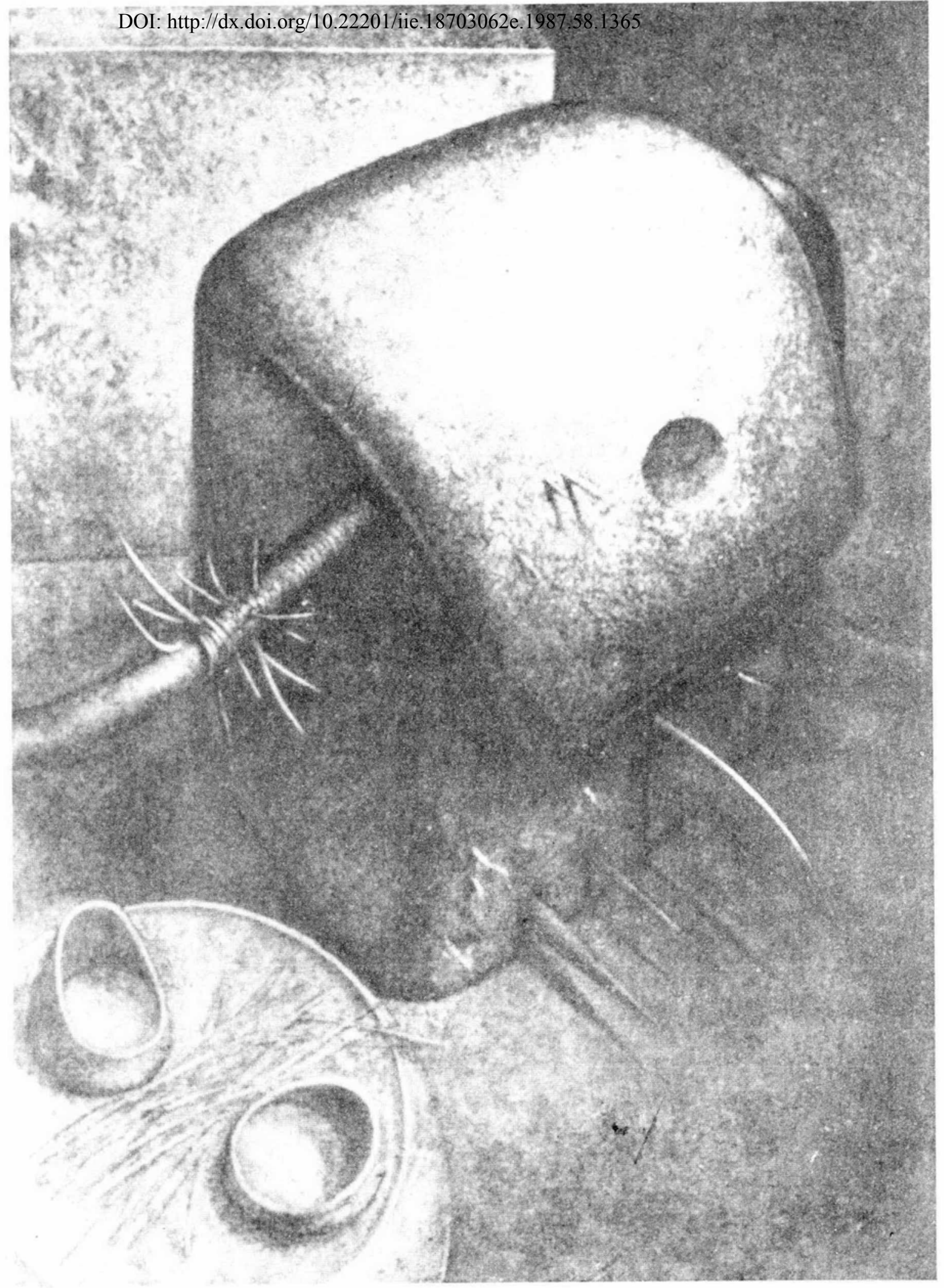

Figura 1. Eduardo Tamariz, Tenía miedo del aire y de la lluvia. Óleo/tela, 1985. 
DOI: http://dx.doi.org/10.22201/iie.18703062e.1987.58.1365

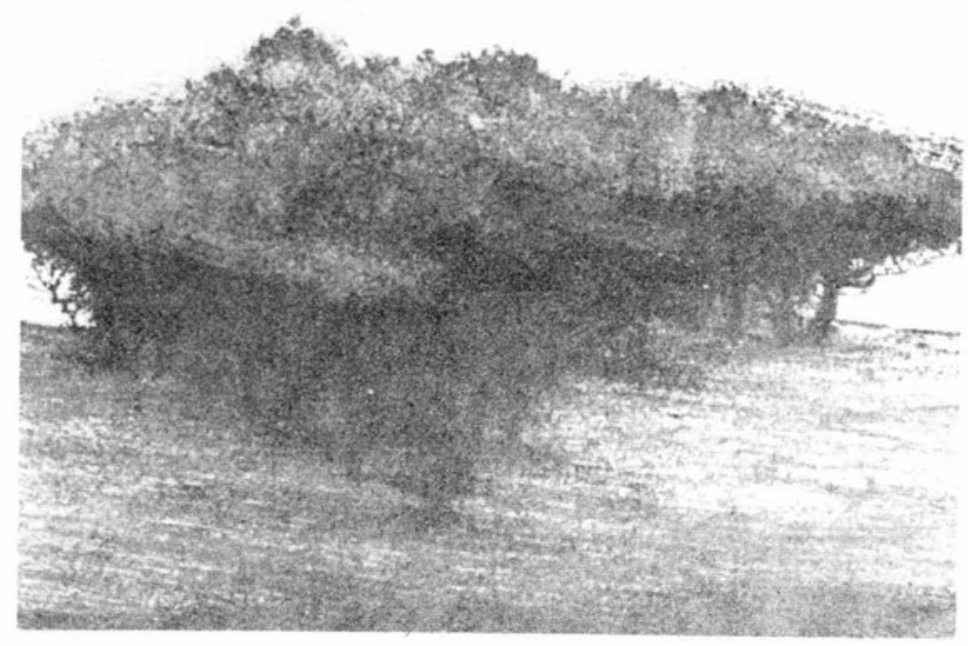

Figura 2. Ricardo Rocha, Apunte del natural. Acrílico/tela, 1985.

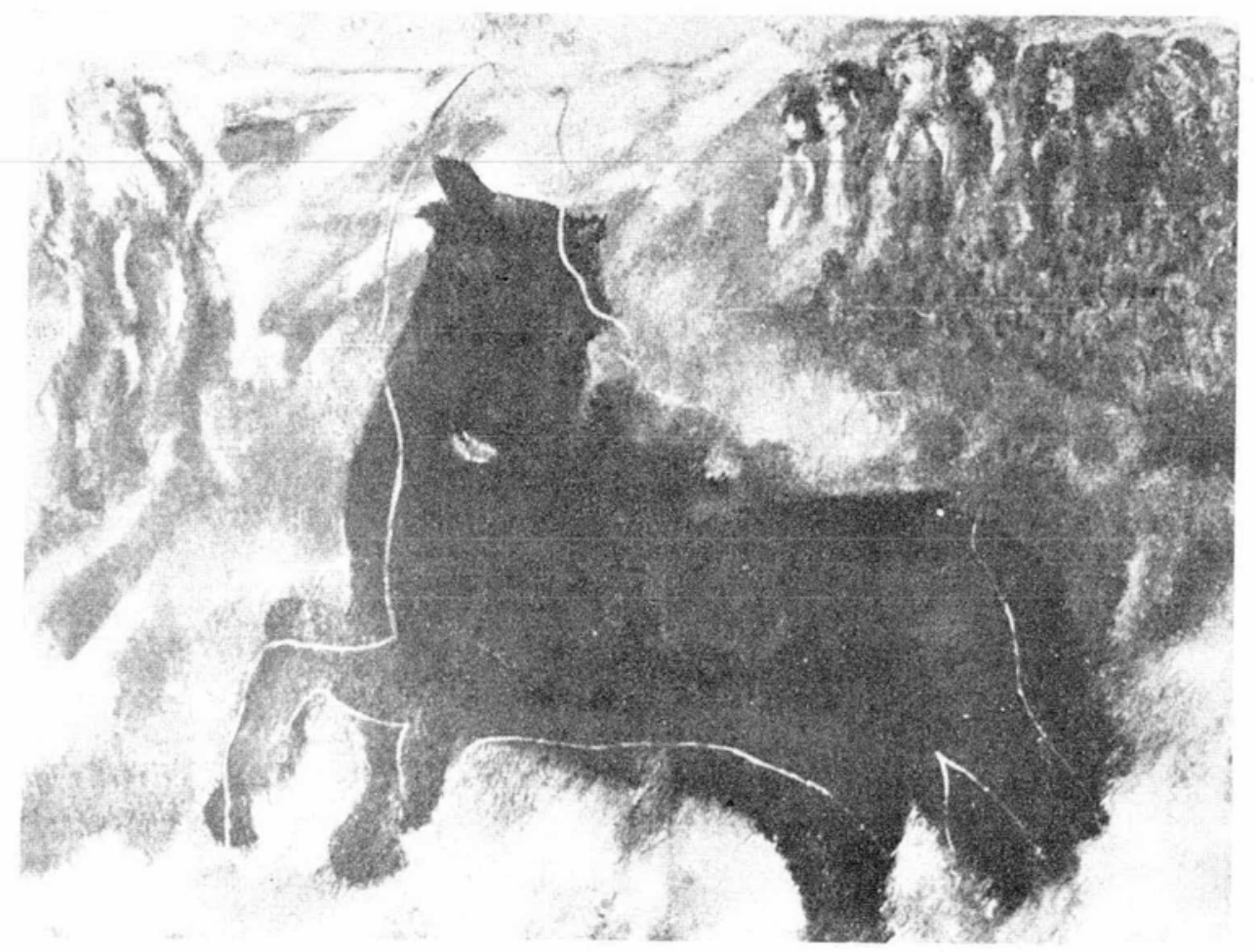

Figura 3. Oscar Rodríguez, Caballo negro tú tienes la cola roja. Oleo/tela, 1985. 


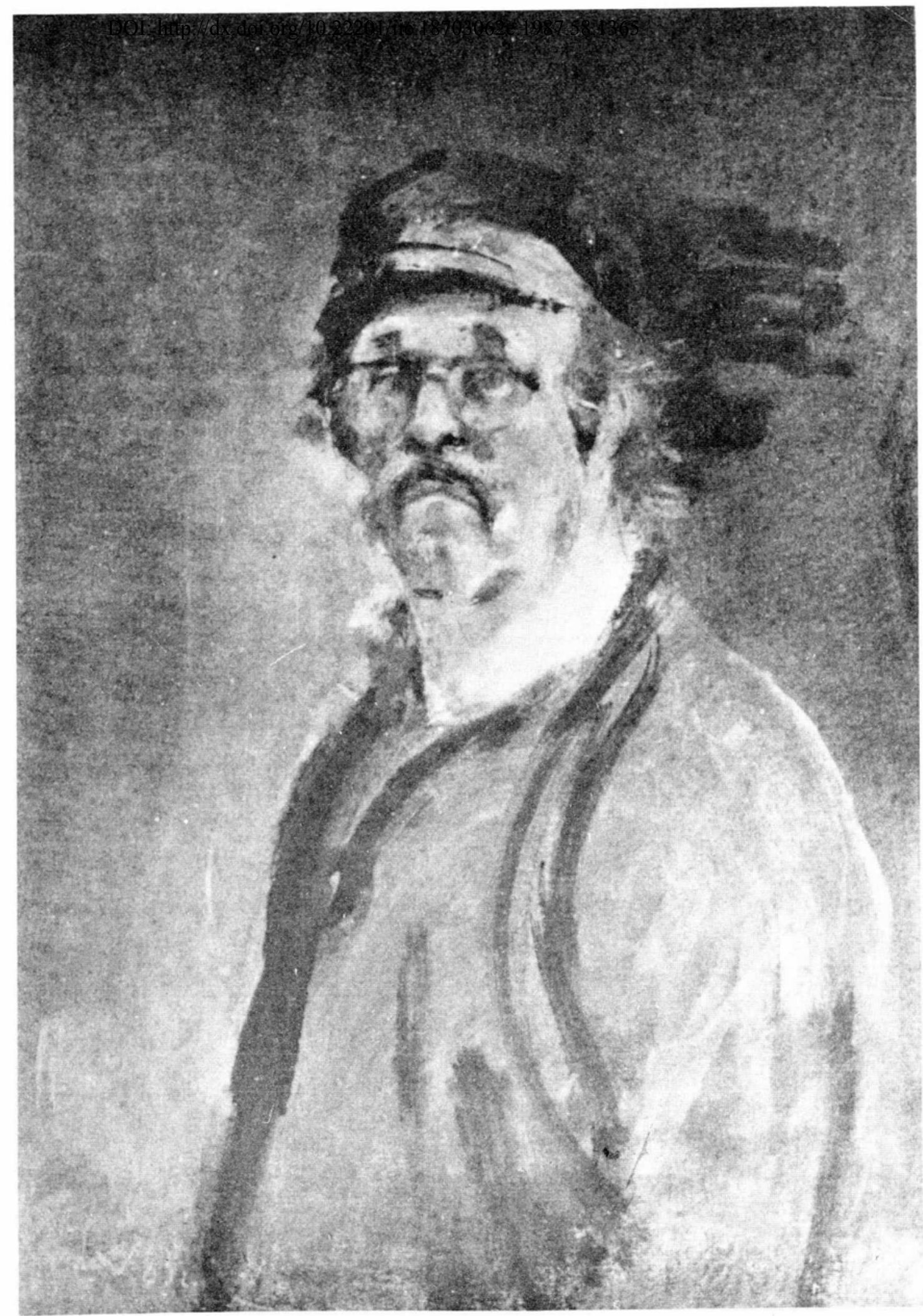

Figura 4. Vlady, Autorretruto. Óleo/tela, 1985. 


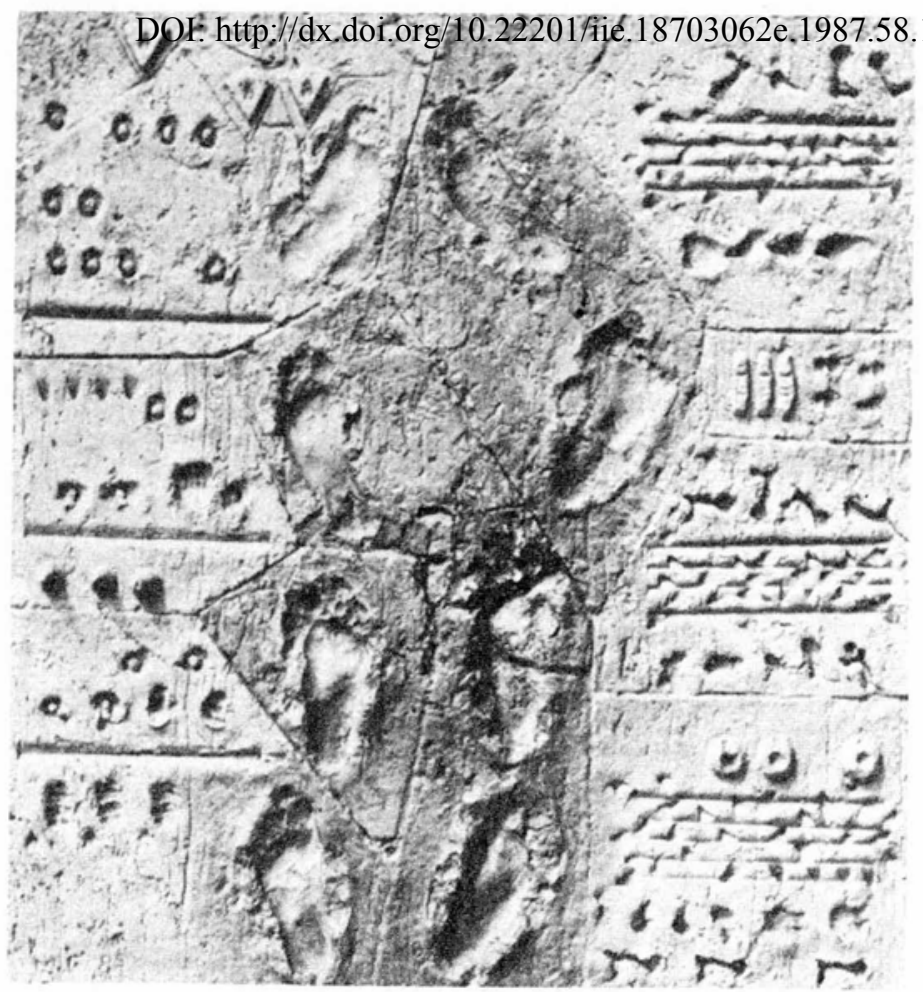

Figura 5. Ismael Guardado, Hastial (detalle). Tierra cocida y técnica mixta (tríptico), 1985.

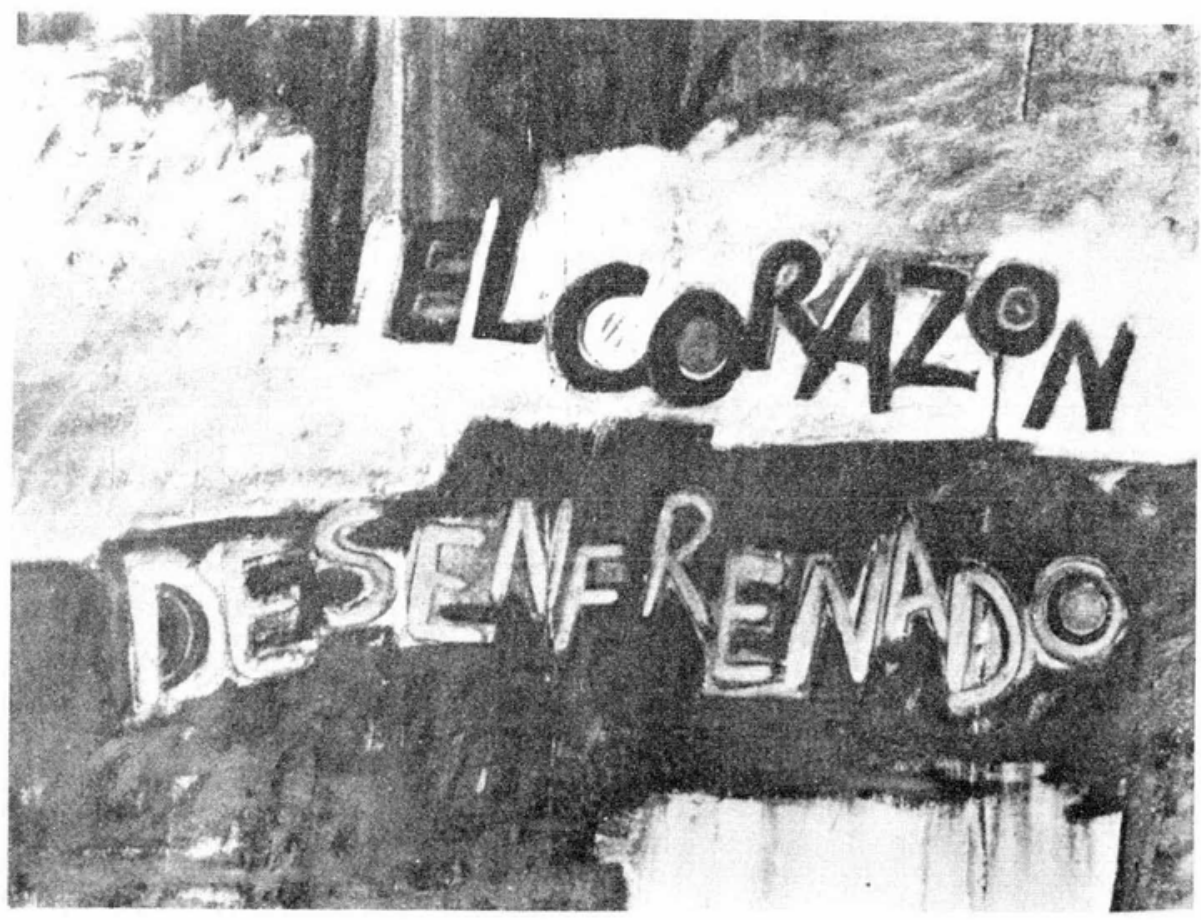

Figura 6. Susana Sierra, Homenaje a Rilke. Óleo/tela, 1985. 
La pintura mexicana de la "generación intermedia" y la de Vlady son un rotundo ejemplo de abstracción experimental que no puede alejarse del realismo, pero un realismo no imitativo que, privilegiadamente, proviene de un estar a medio camino, en el "entre", que es frontera, límite, veta ardiente que separa la individualidad de los objetos y los seres, y despunta de una necesaria anarquía de elementos que permite remover de fondo los preceptos que rigen la composición total de las obras.

\section{BIBLIOGRAFIA}

Alternancias. La generación intermedia, Museo de Arte Moderno, México, diciembre 1985-febrero 1986.

Vlady. Exposición metodológica, Museo del Palacio de Bellas Artes, enero-febreto de 1986.

Worringer, Wilhelm, Abstracción y naturaleza, México, F.C.E., 1953. 